\title{
OR
}

\section{The effects of age, rank and neophobia on social learning in horses}

\author{
Konstanze Krueger $\Omega^{\Omega^{\dagger}}$, Kate Farmer *, Jürgen Heinze ${ }^{\dagger}$ \\ †University of Regensburg, Biology 1, Universitätsstraße 31, 93053 Regensburg, Germany \\ Spresent address: \\ University of Applied Sciences Nürtingen-Geislingen, Neckarsteige 6-10, 72622 Nürtingen, Germany \\ - Centre for Social Learning \& Cognitive Evolution, School of Psychology, University of St Andrews, St An- \\ drews, Scotland KY16 9JP \\ corresponding author: Konstanze Krueger: konstanze-krueger@equine-science.de
}

'The original publication is available at www.springerlink.com' December 2013

Animal Cognition http://doi.org/10.1007/s10071-013-0696-x

\begin{abstract}
Social learning is said to meet the demands of complex environments in which individuals compete over resources and co-operate to share resources. Horses (Equus caballus) were thought to lack social learning skills because they feed on homogenously distributed resources with few reasons for conflict. However, the horse's social environment is complex, which raises the possibility that its capacity for social transfer of feeding behaviour has been underestimated. We conducted a social learning experiment using 30 socially kept horses of different ages. Five horses, one from each group, were chosen as demonstrators, and the remaining 25 horses were designated observers. Observers from each group were allowed to watch their group demonstrator opening a feeding apparatus. We found that young, low ranking, and more exploratory horses learned by observing older members of their own group, and the older the horse, the more slowly it appeared to learn. Social learning may be an adaptive specialisation to the social environment. Older animals may avoid the potential costs of acquiring complex and potentially disadvantageous feeding behaviours from younger group members. We argue that horses show social learning in the context of their social ecology, and that research procedures must take such contexts into account. Misconceptions about the horse's sociality may have hampered earlier studies.
\end{abstract}

Keywords Horse $\cdot$ Social learning Sociality $\cdot$ Ecology . Social relationships

\section{Introduction}

Animals learn through individual or social learning. In individual learning, each animal experiences positive or negative consequences for its own interactions with its environment. In social learning, animals learn by observing another animal or its visual, olfactory or auditory cues (Heyes 1994, Galef 1995). Social learning usually entails information transfer between conspecifics (Whiten et al. 2004, Laland 2004), but social learning between members of different species has also been recorded (e.g.: dogs learning from humans) (Pongrácz et al. 2001 and 2008, Mersmann et al. 2011). By using socially transmitted information, animals adapt to the demands of a society in which individuals have to compete and co-operate for resources such as mating partners, food, sleeping sites, and social status (Galef and Giraldeau 2001, Byrne and Whiten 1988). Furthermore, social learning of novel skills can lead to traditions or cultures, for example the famous potato washing in Japanese macaques (Imanishi 1957). In some species, the expression of social learning correlates with group size (Dunbar 2003), in some with the complexity of social relationships (Dunbar and Shultz 2007), and in some with the frequency of innovative behaviours and tool use (Reader and Laland 2002).

This study investigates the propensity of horses to learn to operate a feeding apparatus by observing a demonstration by another member of their social group. Previous studies have not yielded significant evidence of social transfer of information in the foraging behaviour of horses (Baer et al. 1983, Baker and Crawford 1986, Clarke et al. 1996, Lindberg et al. 1999). It was argued that, as in most other ungulates, the horse's feeding on homogenously distributed resources (Devenport et al. 2005) makes social learning unnecessary (van Schaik 2010). However, recent research shows that horses live in complex social environments which might favour the evolution of social 
transfer of information (Nicol 2002, Murphy and Arkins 2007). Horses form largely stable harems and bachelor groups with clear linear hierarchies (Houpt et al. 1978), and preferentially interact with up to three partners (Tyler 1972). Social groups may temporarily split or merge (Linklater 2000) thus showing a fission-fusion dynamic. Like other animals living in fission-fusion societies (e.g., primates, social carnivores, bats, ungulates, dolphins, and elephants; Kerth2010), horses are capable of social (Krueger and Heinze 2008) and individual recognition (Proops et al. 2009, Krueger and Flauger 2011), of forming alliances for the mutual protection of offspring (Cameron et al. 2009), and of protecting social bonds by third party intervention (Schneider and Krueger 2012). They also show conciliatory behaviour after conflict (Cozzi et al. 2010).

In this study, we examine whether horses show social learning, and if so, how it is affected by the individual and social features of the demonstrators and observers, such as age, social rank, group membership, and neophobia. It has been reported that only young apes (Call 2006), young horses (Nicol 2002), and high ranking, less neophobic birds (Boogert et al. 2006) learn to operate a feeding device in individual learning tests. Neophobia might result in an approach-avoidance conflict when horses are confronted with an experimental apparatus, as in fowls (Murphy 1978). Previous studies demonstrated that individual horses have different levels of neophobia, and therefore different exploratory behaviour (Le Scolan et al. 1997, Momozawa et al. 2003, 2005, Christensen et al. 2005, König von Borstel 2011). Neophobic horses may explore less and therefore learn less in a social learning setup, as has been shown in individual learning in birds (Boogert et al. 2006).

Additionally, social transfer of information may depend on the relationship between observer and demonstrator (Coussi-Korbel and Fragaszy 1995, Russon and Galdikas 1995). For example, observers may prefer to use information provided by high ranking adults, as observed in dogs (Pongrácz et al. 2008), or choose to copy the most experienced and oldest animal, as shown in the acquisition of nut-cracking techniques in chimpanzees and capuchin monkeys (van Schaik 2010). Moreover, the presence of high ranking demonstrators may inhibit the expression of social learning in others. In chimpanzees, the proximity of dominant animals inhibited subordinates from performing a food acquisition task (Chalmeau and Gallo 1993). Furthermore, familiarity with the demonstrating animal may be important for the use of social information (Coussi-Korbel and Fragaszy 1995, Russon and Galdikas 1995), as horses preferentially appear to copy social behaviour of known conspecifics (Krueger and Heinze 2008) and to orientate their exploration behaviour on the focus of attention of well-known humans (Krueger et al. 2011).

In a social learning experiment using 30 socially kept horses of different ages we examined:

I. social transfer of feeding behaviour, and

II. the effect of the observer's age, rank, and exploratory behaviour on social learning performance. In addition, we investigated whether observers
III. learn predominantly from familiar, older and higher ranking horses, and

IV. copy the demonstrator's technique when opening the feeding apparatus.

\section{Methods}

\section{Animals}

We used 44 domestic horses (Equus caballus), including 22 Standardbreds, 8 Trotters, 3 Haflingers, 4 Welsh Cobs, and 7 ponies. The 30 horses which were used in the social learning experiment came from five groups, each of which had had a stable hierarchy for at least 2 years prior to the experiment. These groups consisted of 3 to 12 horses (median $=5$ ) and were kept in open stabling. The horses were between 2 and 28 years old (median $=11$ years) and included 9 geldings and 21 mares. One horse from each group was chosen to be the demonstrator for its group and the rest of the horses were observers (Table ESM 5).

The 14 horses ( 5 geldings and 9 mares) used in the double-blind control experiment were kept in open stabling during the day and in individual boxes overnight. The overnight separation of the control horses was not considered likely to affect their familiarity with each other, as horses from this type of management have been shown to be able to individually identify their group members (Proops et al. 2009) and to have excellent long-term memory (Hanggi and Ingersoll 2009). The control horses were chosen from three groups which comprised 4, 8 and 10 animals. They were selected so that the age span of the control horses ( 2 to 25 years, median $=9.5$ years) was comparable to that of the test horses (Table ESM 6).

Most animals were unrelated except for two motheroffspring pairs which were used as observers to avoid any possible bias through mother-offspring information transfer (e.g. vertical social information transfer, Heyes and Galef 1996). All horses were in excellent feeding condition. Their regular feed comprised hay and a compound feed, with access to grass in their pastures.

The study has been conducted according to relevant national and international guidelines.

Permissions from the regulatory authority for animal welfare were not needed for the present non-invasive behaviour study. The experimental procedures described in this study are not considered "experiments on animals" according to the German Animal Protection Law (Deutsches Tierschutzgesetz). All horses were privately owned. The horse owners lived close to the experimenters' location, Regensburg, took notice of the study through word-of-mouth recommendation, and offered their horses for participation. They were all informed about the experimental procedure before the study was started and gave informed permission for their horses to participate. All the offered horses were used in the study, except in one case, where one owner owned several groups of horses and only the group with horses of most evenly distributed ages was used. 


\section{Experimental set-up}

The experimental apparatus was a box, $60 \mathrm{~cm}$ long, $35 \mathrm{~cm}$ wide, and only $10 \mathrm{~cm}$ high (Fig. $1 b$ ). We chose these dimensions as horses' visual discrimination is best at ground level (Hall et al. 2003). The box had a drawer measuring $21.5 \mathrm{~cm} \times 19 \mathrm{~cm} \times 5.5 \mathrm{~cm}$ on one side that could be opened by pulling a rope on the opposite side of the box. The distance between the drawer and the rope was, about $50 \mathrm{~cm}$. Pulling the rope released a scroll spring that pushed the drawer open. The box was fixed on a $90 \mathrm{~cm} \mathrm{x}$ $75 \mathrm{~cm} \times 2 \mathrm{~cm}$ baseplate to ensure stability, and was placed in the middle of a $20 \times 20$ metre area. Pieces of carrot and bread were put into the drawer. To open the drawer, the horses had to pull the rope, which was green and blue in colour to distinguish it from the brown of the box. Horses discriminate colours at the spectral peak of $539 \mathrm{~nm}$ and 428nm (Macuda and Timney 1999, Carroll et al. 2001, Hanggi et al. 2007) and the brightness of up to 18 colours (Hall et al. 2003, Geisbauer et al. 2004).

\section{Demonstrator training}

From the 30 social learning experiment horses, we trained 5 middle ranking horses of close to average age and object neophobia $(N=5$, median $\mathrm{ADI}=0.62$. range $=0.38$; median age $=15$, range $=10$, median object neophobia $=6$ touches, range $=3$ ) to be the demonstrators. Each demonstrator only demonstrated to members of its own group, to ensure familiarity between demonstrator and observers (Krueger and Heinze 2008). During training, demonstrators learned to pull the rope on the experimental apparatus to open the drawer (Fig. 1b; video ESM 3). The drawer contained pieces of bread and carrot, which the horse was allowed to eat after successfully opening the drawer.

For the training phase, each of the 5 demonstrators was led into the experimental area and first habituated to the experimental box. It was considered habituated when it was calm and showed no fear (between 10 and 60 minutes). Then, a piece of bread was tied to the rope. When the demonstrator tried to eat the bread it coincidentally pulled the rope and opened the drawer. The demonstrator was then allowed to eat the food inside. Between 20 and 40 repetitions were needed before they opened the drawer even without bread being fixed to the rope. We then continued for up to 40 repetitions until the demonstrator reached the learning criteria of spontaneously approaching and operating the feeding drawer 10 times in a row (video ESM 3). This took the demonstrators 2 to 4 days, with 20 training units per day.

\section{Experimental procedure}

The horses not chosen to be demonstrators were used as observers. Observers were randomly collected from the particular demonstrator's social group, one at a time, and led to the experimental area, where each received food from the open drawer 5 times in a row. This both habituated the observer horse to the experimental box and motivated it to search for food. All observer horses searched for food at the box after habituation. Therefore, habituation trials were not repeated on the following test days.

For the test phase, the demonstrator horse was led to the 'demonstrator starting position', about 8 metres from the apparatus. An observer horse from the demonstrator's
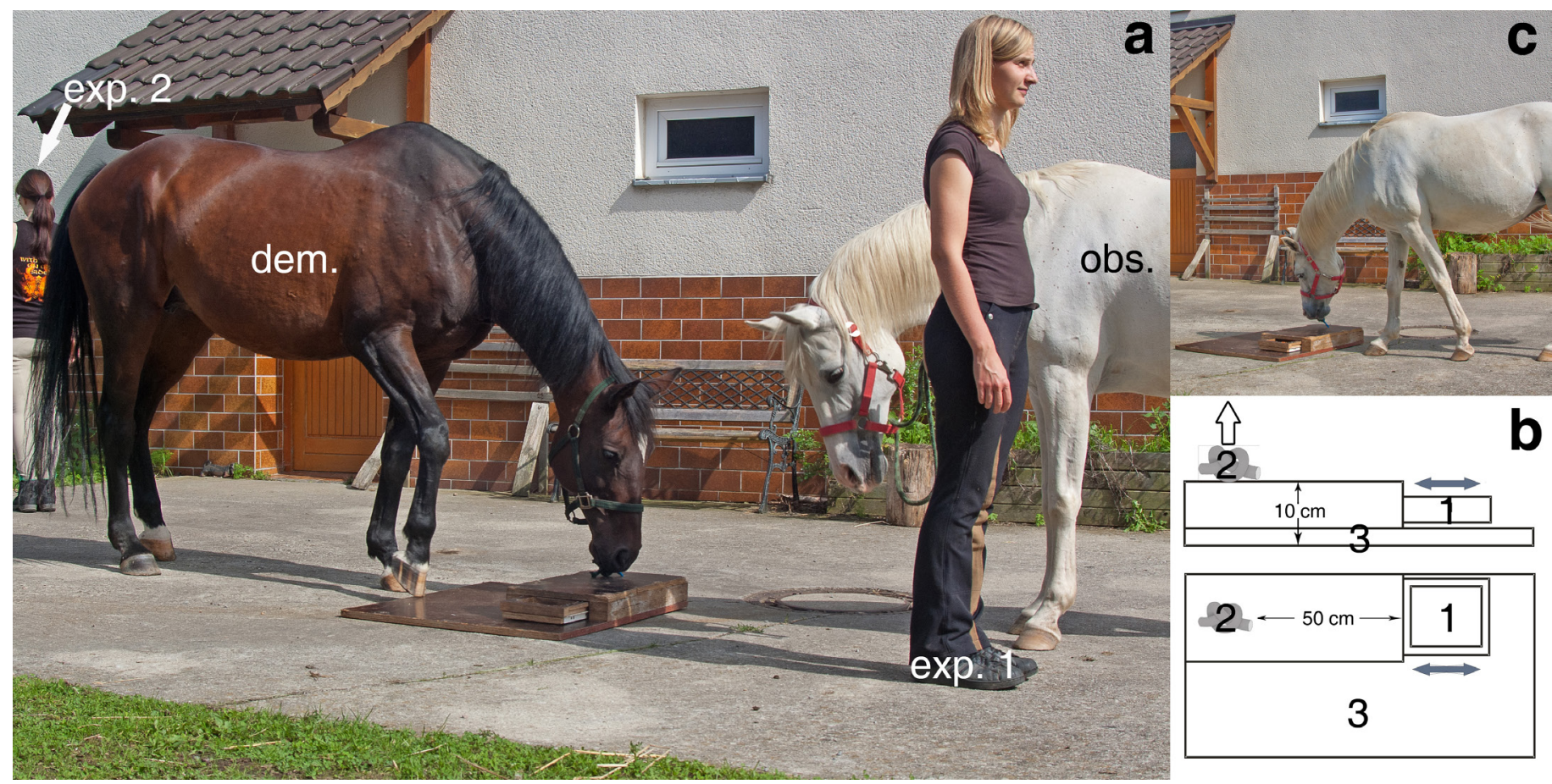

Fig. 1 Experimental set-up

(a) Demonstration exp1: experimenter 1 in waiting position; dem: demonstrator horse in demonstration position, ex-app: experimental apparatus; obs: observer horse in observation position; exp2: experimenter 2 for handling the observer horse. Only the central part of the experimental area is shown. (b) Experimental apparatus, 1: drawer, the arrow depicts the direction in which it opens; 2: rope, the arrow depicts the direction it had to be pulled to open the drawer; 3 : stabilising base-plate. The distance between the rope and the drawer is $50 \mathrm{~cm}$, and the box is $10 \mathrm{~cm}$ high. (c) Successful learner opens the drawer by pulling the rope. 
group was held, facing the demonstrator, with its front feet approximately 1 metre away from the box as, in some species, proximity has been shown to be crucial for the motivation to learn. Then the demonstrator was released and allowed to operate the feeding drawer as in the training phase (Fig. 1a; video ESM 4).

After opening the drawer and retrieving the food, the demonstrator was then led away. Demonstrators never failed to demonstrate the task. Thereafter, the drawer was refilled with food and closed, the observer was immediately released, and the experimenters left the experimental area. Observer horses were left in the experimental area for 5 minutes after each demonstration, but none of the observer horses tried to manipulate the feeding device for longer than 5 minutes in any one trial. They either approached it immediately or not at all, and if they were not successful in opening it, they quickly lost interest. Prior to the experiment, the maximum number of demonstrations was set at 120, with 10 to 20 demonstrations on a minimum of 6 and a maximum of 8 consecutive days, depending on the horse's motivation to participate.

Observer horses were counted as successful learners when they opened the drawer (Fig. 1c; video ESM 4), and to have reached learning criteria when they opened the drawer 10 times consecutively with demonstration by the demonstrator horse, and then 10 times consecutively without demonstration (Fig. 5). Learner horses did not receive any further demonstrations after reaching learning criteria. For the trials without demonstration the procedure was similar to the procedure for the control group (see: "Control experiment").

Observers were designated 'non-learner' if they lost interest and refused to approach the experimental apparatus after 10 demonstrations in a row on at least 2 consecutive days, or if they did not reach the learning criteria after the maximum of 120 demonstrations. All non-learner horses received 120 demonstrations, even when they had lost interest much earlier, to ensure equal opportunities for learning by trial and error, and to ensure they had the opportunity to regain interest in the feeding device at a later time point. However, this was never the case.

\section{Experimenter}

Three experimenters participated in each test: Experimenter 1 handled the demonstrator horse, holding it at the starting position, releasing it to perform its task, and collecting it after demonstration. Experimenter 1 faced away from the experimental area during the performance of the observer horse (Fig. 1a).

Experimenter 2 handled the observer horse during each demonstration (Fig. 1a), keeping it on a loose lead while turning her back to the experimental apparatus and looking away towards a predetermined point, and avoiding any bodily contact with the observer. After the demonstration, she released the observer horse and left the experimental area (video ESM 4). It was necessary to keep the observer horse on a lead rope to prevent it from monopolizing the feeding device (as happens in hens, Nicol and Pope 1999), or from scrounging the food found by the demonstrator
(Giraldeau and Lefebvre 1987).

Experimenter 3 videotaped and wrote down a description of the horse's behaviour from behind a cover outside the experimental area, and also refilled the drawer (video ESM 4). Observer and control horses were allowed to see the refilling process to avoid feature negative effects, which cause some species not to search for food in areas where others had fed before (Hopewell et al. 2010). When refilling, experimenter 3 was careful to distribute possible local enhancement cues evenly. He / she entered the experimental area, squatted down between the observer horse and the experimental apparatus, centred herself between the drawer and the rope, touched the box on the rope side with one hand, placed the food in the drawer with the other hand and closed the drawer. Throughout the refilling process he/she faced away from the horse towards the opposite wall.

The experimenters of the present study have given written informed consent for their photographs and videos to be published.

\section{Control experiment}

The control experiment was conducted in the same manner as the social learning experiment, but without a demonstrator horse showing how to open the drawer. The control horses received the same habituation procedure, being taken, one at a time, from their social groups and led into the experimental area and allowed to feed from the open drawer 5 times in a row. Thereafter, they had 120 trials in which they had 5 minutes to approach the box and manipulate the apparatus in the experimental area.

As in the experimental procedure, the control horse was placed in the starting position, with its front feet approximately 1 metre away from the box. The drawer was open, with no food in it, as if the demonstrator horses had just fed from it. Experimenter 3 filled the drawer with food in the horse's view, then closed it and left the experimental area. The control horse was released and experimenter 2 left the area. If the control horse did not make any attempt to open the feeding drawer, or gave up trying and walked away, experimenter 2 returned, took it by the halter, and turned it around so that it could not see the device while experimenter 3 opened the drawer and took the food out. Then the control horse was led back to the starting position and placed with its front feet approximately 1 metre from the box for the next trial. If the horse was successful in opening the drawer it was allowed to eat the food, then experimenter 2 returned and led it back to the starting position. Removing the food for unsuccessful control horses was done to align the control trials with the experimental trails. In experimental trials, either the demonstrator consumed the food during the next demonstration or observer horses consumed the food themselves when they reached learning criteria. As in the experimental trials, experimenter 3 refilled the drawer for each trial to demonstrate that there was still food in the drawer and to avoid feature negative effects (Feist and McCullough 1976). The only aspect that differed between experimental and control trials was that the control horses 
did not receive any demonstration of how to open the drawer from a demonstrator horse.

\section{Dominance relationships}

Before the experiment, we determined the dominance relationships among the horses in the field by continuously sampling agonistic encounters, such as approaches, retreats, threats to bite or kick, bites, kicks and chases (Feist and McCullough 1976, McDonnell and Haviland 1995, McDonnell 2003), over six hours, distributed over daylight hours on at least three different days. We used a modified average dominance index (ADI) for the analysis of the dominance ranks. It is calculated as follows: The dominance index per pair of individuals, $\mathrm{w}_{\mathrm{ij}}$ is the number of times an individual $i$ won against a certain opponent $j$ $\left(\mathrm{x}_{\mathrm{ij}}\right)$ divided by the total number of agonistic encounters within the pair $\left(\mathrm{x}_{\mathrm{ij}}+\mathrm{x}_{\mathrm{ji}}\right)$. It thus becomes, $\mathrm{w}_{\mathrm{ij}}=\mathrm{x}_{\mathrm{ij}} /\left(\mathrm{x}_{\mathrm{ij}}+\right.$ $\mathrm{x}_{\mathrm{ji}}$ ). Individuals were counted as a winner when their interaction partner retreated one step or more. Pairs of individuals that were not involved in an encounter with each other were excluded from the analysis. The average dominance index of an individual is the average of all its dominance indices with all its interaction partners, thus $\frac{1}{N} \sum W_{i j}$ ADI values range from 0 to 1 , a high value al. 2005).

\section{Novel Object Test}

Prior to the social learning test, we assessed the horses' exploratory behaviour using a novel object test (Wilson et al. 1994, Mettke-Hofmann et al. 2002, Boogert et al. 2006, Christensen et al. 2005). Horses were individually tested in a $4 \times 4$ metre enclosure for their propensity to touch six different unknown objects, which were presented in random order (a blue bucket, an orange umbrella, a yellow truck-chock, a blue cushion, a pink gymnastics-mat, and a blue-red-white coloured ball). Members of the test horse's group were in sight to reduce anxiety, but the novel objects were only visible to the test horse.

The individuals' total touches ranged from 0 to 13 (median $=4$ touches). From this we calculated the animal's exploration index by dividing the total number of touches by the number of objects. The exploration index was placed on a shy-bold scale, where shy animals touched the objects less often and had a lower index and bold animals more often and had a higher index (Wilson et al. 1994, Boogert et al. 2006).

\section{Statistics}

We applied the statistical software SPSS 20 and the R-project statistical environment (2012). We used the software Eureqa (Schmidt and Lipson 2009), supplied by http://creativemachines.cornell.edu/eureqa to calculate the equation for the mathematical relationship of age and learning speed. As some variables were not normally distributed (KS-test) we applied non-parametric or semiparametric tests. Differences in outcome between learning and control test were evaluated by applying a Fisher's exact test. Main effects on learning were tested with semiparametric Generalized Estimating Equations (GEE). The horses' membership in a particular group and sex were not significant, but age, object neophobia (GEE, $N=25$, age: $\chi^{2}=6.2, p=0.01$; temperament: $\left.\chi^{2}=6.99, p=0.008\right)$, and rank were significant after reshuffling (GEE, $N=25, \chi^{2}$ $=3.76, p=0.05)$. Therefore, we continued with separate analysis by applying Mann-Whitney $U$ Exact-tests to independent datasets, Wilcoxon signed rank Exact-tests to dependent datasets, Binomial Exact-test to binomial outcome data, and Spearman rho tests for correlations. Fisher combination tests were used to draw conclusions on separate data presented in table 1. All tests were twotailed. $P$ was set at 0.05 and corrected by a Sequential Bonferroni Procedure after multiple testing.

\section{Results}

All the observers and all the control horses approached the feeding apparatus after being habituated, with a median latency of $5 \mathrm{sec}$ (range: 3 to $30 \mathrm{sec}$ ) for observer horses and a median latency of $5 \mathrm{sec}$ (range: 3 to $11 \mathrm{sec}$ ) for control horses.

Of the 25 observer horses, 12 learned to operate the

Table 1 The effect of age, rank and object neophobia on learning.

\begin{tabular}{|c|c|c|c|c|c|}
\hline \multirow[t]{3}{*}{ learners $(\mathrm{N}=12)$} & \multicolumn{2}{|c|}{$\begin{array}{l}\text { versus non-learners } \\
(\mathrm{N}=13)\end{array}$} & $\begin{array}{l}\text { versus } \\
\text { demonstrators } \\
(\mathrm{N}=5)\end{array}$ & \multicolumn{2}{|c|}{ Tearning speed } \\
\hline & $\begin{array}{l}\text { Mann-Whi } \\
(\mathrm{N}=25)\end{array}$ & U exact test & $\begin{array}{l}\text { Binomial Exact-test } \\
(\mathrm{N}=12)\end{array}$ & $\begin{array}{l}\text { Spearman } \\
(\mathrm{N}=12)\end{array}$ & correlation \\
\hline & Z & $P$ & $P$ & $\mathrm{r}_{\mathrm{s}}$ & $P$ \\
\hline Age & -2.84 & $0.003^{*}$ & $0.02^{*}$ & 0.65 & $0.02^{*}$ \\
\hline rank (ADI) & -1.96 & $0.05^{*}$ & 0.05 & 0.53 & 0.07 \\
\hline object neophobia & -2.74 & $0.005^{*}$ & 0.05 & 0.07 & 0.83 \\
\hline
\end{tabular}


experimental apparatus after observing the demonstrations (Fig. 1 to 4; video ESM 4; Table ESM 5). The 12 learners took a median of 12 trials (range: 2 to 59 trials) until they opened the drawer for the first time, and a median of 45 trials (range: 29 to 106 trials) to reach learning criteria (Fig. 5). The 13 observers which did not learn the task lost interest in the device at a median of 58 trials (range: 3 to 120 trials). The time the 12 learners needed to manipulate the rope decreased significantly from the first success to the subsequent openings of the drawer (first time, median $=22 \mathrm{sec}$, range: 10 to $33 \mathrm{sec}$; later trials, median $=4 \mathrm{sec}$, range: 3 to $5 \mathrm{sec}$; Wilcoxon signed rank Exact-test: $N=12$, $Z=-3.06, p=0.003$ ).

Significantly fewer of the control horses (2 out of 14)

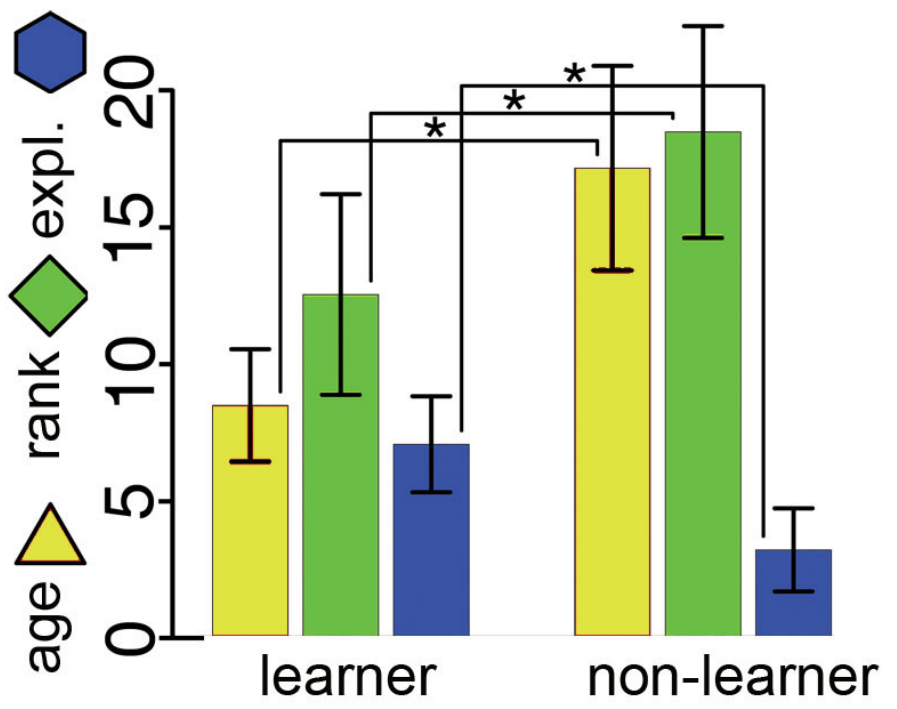

Fig. 2 Learners and non-learners

Learners were younger, lower ranking (ADI) and more exploratory (exploration index $=$ explor) than non-learners (Fisher's combination test, $\mathrm{N}=3, \mathrm{X}^{2}=28.21, \mathrm{p}=0.005$; Table 1 and S1). For a better overview, social rank was depicted by multiplying the horses' ADI values by 10 . The columns depict the mean, and the whiskers the SD. Significant relationships are connected by edges. * stands for $p \leq 0.05$.

learned to operate the drawer by individual learning only i.e. with no opportunity for social learning (Fisher's exact test: $p=0.04$; Table ESM 6). The 2 control horses which learned the task needed between 19 and 59 trials before they opened the drawer for the first time, and between 77 and 81 trials to reach learning criteria (Fig. 5). The 12 control horses which did not learn the task lost interest in the feeding apparatus significantly faster (median $=20$ trials, range: $5-54 \mathrm{sec}$ ) than the 13 'non-learner' observer horses (median $=58$ trials, range: 3 to $120 \mathrm{sec}$ ) (MannWhitney $U$ Exact-test: $\mathrm{N} 1=12, \mathrm{~N} 2=12, Z=-3.32$, p $<0.001)$. Furthermore, the 14 control horses needed significantly more time before they manipulated the rope area for the first time (median $=44 \mathrm{sec}$, range: 20 to 69 $\mathrm{sec}$ ), than the 25 observer horses (median $=27 \mathrm{sec}$, range: 10 to $55 \mathrm{sec}$, Mann-Whitney $U$ Exact-test: $\mathrm{N} 1=14$, N2 = $25, \mathrm{Z}=-3.42, \mathrm{p}<0.001)$.

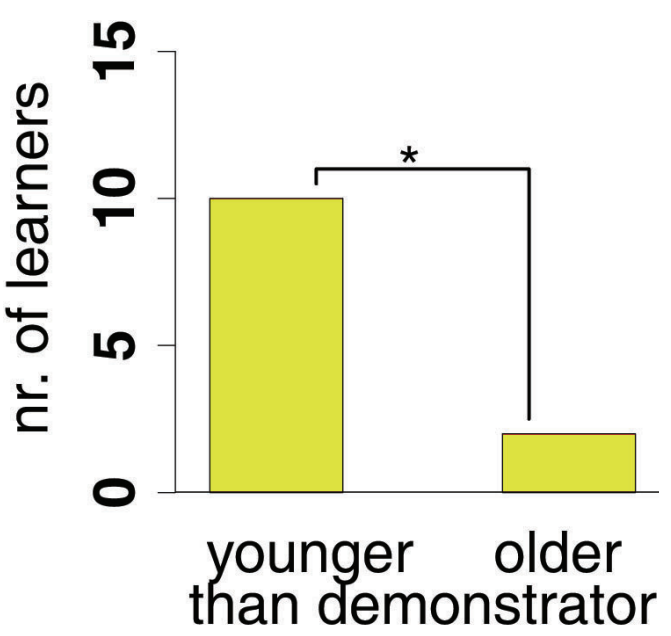

Fig. 3 Learners were significantly younger than demonstrators (Table 1 and S1)

Significant relationships are connected by edges. * stands for $p \leq 0.05$.

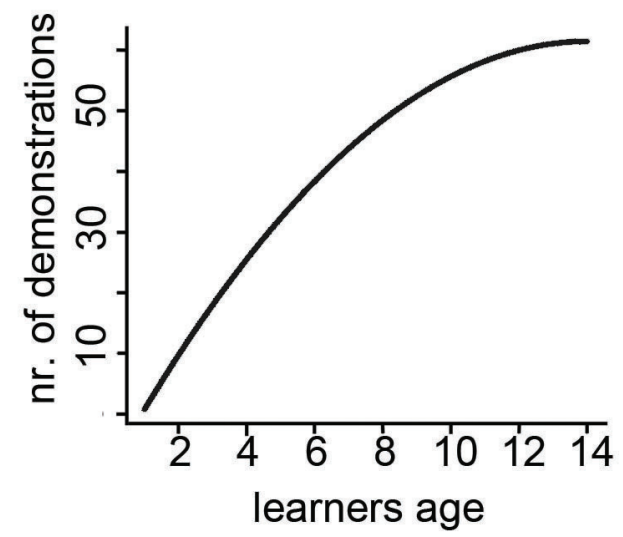

Fig. 4 Learning speed

Learners were faster (needed fewer demonstrations) the younger they were (table 1). The distribution curve was calculated from the horses' ages and the number of demonstrations by using the equation: $10^{*}$ age $-0.36^{*}$ age $^{2}-9$ (Eureqa 2009, Schmidt and Lipson 2009, http://creativemachines.cornell.edu/ eureqa). The raw data used for this graph is shown in supporting figure S2 and supporting table S1.

\section{The effect of age, rank and neophobia on learning}

All learners were between 2 and 15 years old. The learners in the social learning test were significantly younger, lower ranking, and more exploratory than the non-learners (Tables 1 and ESM 1; Fig. 2), and also significantly younger, but not lower ranking or more exploratory, than the demonstrator horses (Tables 1 and ESM 5; Fig. 3; Fig. ESM 1). The younger a horse was, the faster it reached learning criteria (i.e. the fewer demonstrations it needed) (Figure 4; supporting Figure S2; Table S1). However, the learner's rank or exploration index did not have a significant effect on learning speed (Table 1; Fig. ESM 2). When considering figures 2,3 , and 4 , age appears to be the most influential factor for social learning in horses (Fisher's combination test, $N=3, \chi^{2}=27.71, p=0.006$, Table 1).

\section{Rope manipulation techniques}

The 12 learners used several different techniques to open the drawer (Fig. 5; Table ESM 5). 6 learners used the same technique as the demonstrator, and pulled the rope with 


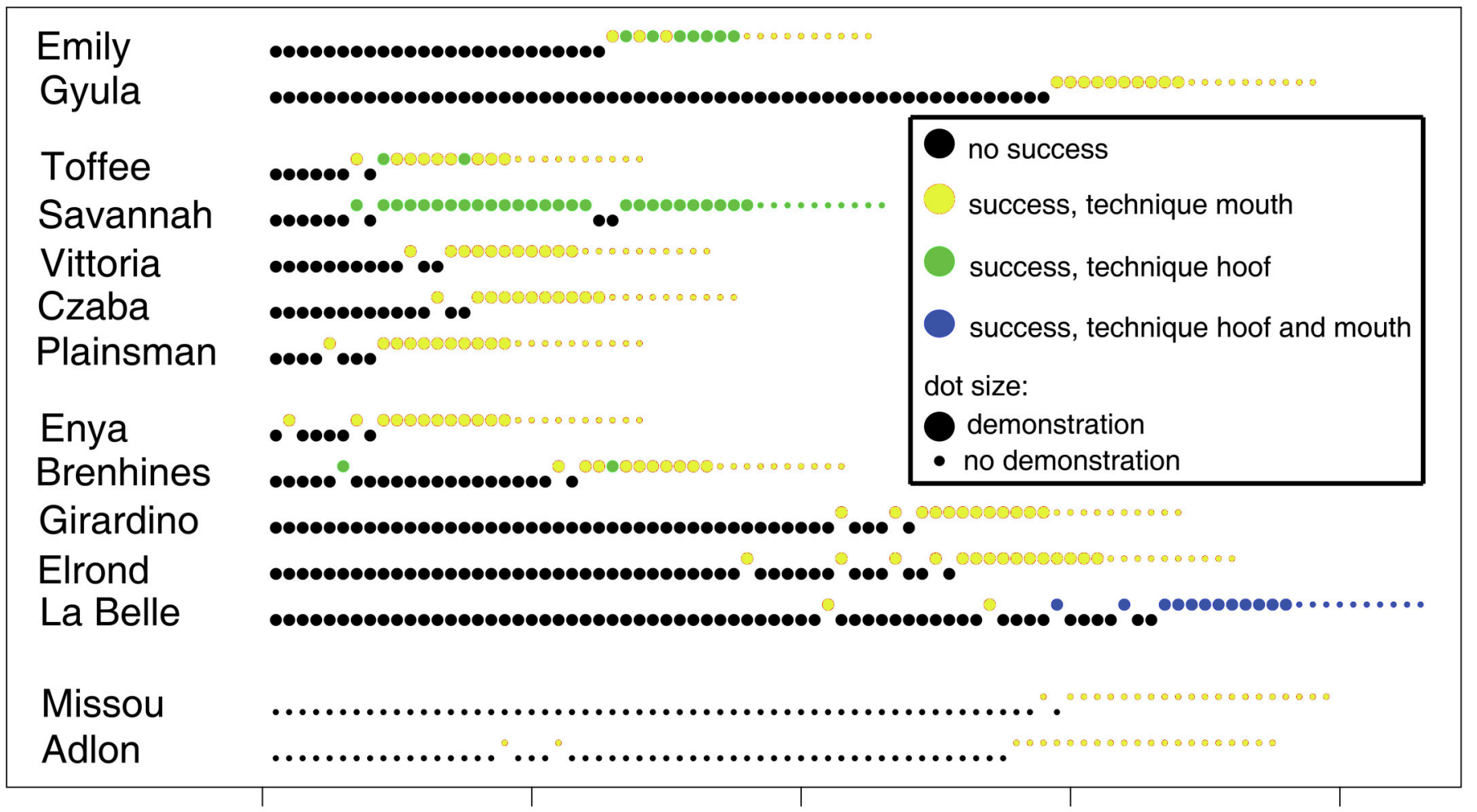

Fig. 5 Drawer-Manipulation Techniques and Consistency

The upper 12 horses were observers from the social learning experiment; the lower 2 horses were control horses that did not receive any demonstration. Trials in which the task was demonstrated are depicted with large dots, and trials without any demonstration with small dots. In the social learning experiment, 2 learners observed the demonstrator and then consistently opened the feeding apparatus by using the rope, 5 manipulated the drawer up to three times after first opening the apparatus and were then consistent in opening, and 5 needed several demonstrations before achieving consistency in opening the feeding apparatus by using the rope. With only one exception, all learners which manipulated the rope with their hoof returned to using the mouth or a mixed hoof-mouth technique after further observation

their mouths. One learner used a hoof to scratch on the rope to open the drawer, and 5 learners used their mouth and a hoof to manipulate the rope in turns or both (mixed technique). Horses which used the same technique as the demonstrators needed longer to open the box for the first time than those using other techniques, such as hoof or hoof and mouth, but this was not significant (Mann-Whitney U Exact-test: $N=12, Z=-1.21, p=0.24)$. The 2 successful control horses used their mouths to pull the rope and open the drawer (Fig. 5; Table ESM 6).

\section{Consistency in learning}

The 12 learners varied in how consistently they opened the drawer (Fig. 5): 2 horses managed to open the feeding apparatus repeatedly after opening it for the first time, but 10 horses needed further demonstrations, and 5 of these needed 1 to 3 additional repetitions before they consistently opened the drawer $(N=5$, media 2 , range $=2)$. After pulling the rope and opening the drawer the first time, these 5 horses were attracted to the drawer (i.e. where they had previously been rewarded) and unsuccessfully tried to open it by directly manipulating the closed drawer and not by pulling the rope, but they reverted to using the rope with further demonstrations. A further 5 horses needed 4 to 21 additional demonstrations $(N=5$, median $=12$, range $=17)$ and switched between manipulating the rope and the drawer. One observer horse opened the box by pulling the rope with its mouth in trial 20, but did not reach learning criteria by trial 120. The consistency of opening the drawer did not correlate with the use of a certain technique (Spearman rank correlation test: $N=12, r=-0.136, p=0.67)$.

\section{Discussion}

This study is the first to clearly demonstrate social transfer of feeding behaviour in horses. By observing a demonstrator, the horses learned the connection between action and outcome at $50 \mathrm{~cm}$ spatially separated areas, and they learned a novel manipulation technique to acquire food from an unfamiliar feeding device. This fulfils the criteria for social learning (Byrne 2002, Whiten et al. 2004). The expression of social learning in horses appears to depend on their age and rank, as in individual learning in apes, birds and horses (Nicol 2002, Call 2006, Boogert et al. 2006), and on their tendency to explore novel objects. In the following paragraphs we discuss several aspects of our observations.

\section{Social transfer of feeding behaviour: ability or stra- tegy?}

\section{Who copies?}

Social learners were younger, lower ranking and displayed more exploratory behaviour than non-learners. Social learning could be age-limited simply because young animals learn better, as in individual learning (Nicol 2002, Call 2006), but it remains difficult to clearly distinguish between the importance of age, rank and exploration for social learning abilities in horses. Both rank and exploration may have been linked to the horses' age as, 
in horses, age usually correlates with rank. Most young horses start at the bottom of their group's social hierarchy and rise in rank as they grow older (Houpt et al. 1978). Additionally, young horses were shown to be more exploratory in the non-social novel object test conducted here, and in other studies (Vidament 2012). The observed enhanced exploratory behaviour of young horses is in line with findings that young horses are more active in a novel object test (König von Borstel et al. 2011)

\section{Whom to copy?}

Horses may decide from whom to learn, to avoid copying wrong behaviour. Usually, animals benefit from learning socially, but there is also the risk of learning disadvantageous behaviour (Giraldeau et al. 2002). Interestingly, the learners in the present study were younger than the demonstrators, but neither rank nor neophobia were significant factors. Age may be decisive because older horses refrain from copying the behaviour of younger animals

(Lefebvre and Giraldeau 1996, Laland 2004, Krueger and Heinze 2008), as young horses might spread incorrect information about food quality, e.g., by eating unfamiliar, potentially dangerous forage (Nicol 2002) which old horses know from previous experience to be unpalatable or dangerous..

Other studies have suggested that dominant animals may displace subordinates from limited food sources after watching subordinates find them (Hare et al. 2001, Valone and Templeton 2002). This would carry much lower time and effort costs than learning a specific feeding behaviour. However, rank was not a significant factor in this study, and horses have not been shown to use conspecifics as reference points when feeding on unlimited resources (Krueger and Flauger 2008),although it is not yet known whether rank is a factor when resources are limited.

Finally, the horses' neophobia may not have inhibited social learning in this test, as neophobic animals did not have to approach the feeding apparatus, but could learn how to operate it by observing the demonstrator from a distance (Heyes 1994, Galef 1995). Furthermore, the horses' exploration behaviour could have been affected by the habituation to the experimental set-up (Christensen et al. 2006) and observers may have been less anxious when calm group members demonstrated the task (Christensen et al. 2008) in the present study.

While age seems to be one decisive factor, it is still unclear whether rank or neophobia play a role in the observer-demonstrator relationship. This needs to be further investigated by testing pairs of observer and demonstrator horses of various age, rank, exploration index, and familiarity under our experimental conditions.

\section{Learning mechanisms}

From the differences in behaviour between observer and control horses, we can try to determine which learning mechanisms may have been involved. The fact that most learners manipulated the whole feeding apparatus before being successful for the first time indicates that trial and error was part of the learning process. However, observers started manipulating the rope area significantly earlier than control horses, and non-learner observers were interested in the device for much longer than non-learner control horses. This indicates that social information may have been transferred either through stimulus or local enhancement (as in dogs, Mersmann et al. 2011, lemon sharks, Guttridge et al. 2013, and elephants, Greco et al. 2013). The horses may have learned through being attracted either to the task by another individual's action (i.e. stimulus enhancement), or to the location where the demonstrator manipulated the feeding apparatus (i.e. local enhancement) (Whiten and Ham 1992, Heyes 1994, Galef 1995 Byrne and Russon 1998, Whiten et al. 2004). This is comparable to bottle-opening by garden birds. The birds learned to open foil-topped milk bottles by being attracted to the area (local enhancement) where demonstrator birds pecked the foil (stimulus enhancement) (Sherry and Galef 1984)

Horses that used a hoof to scratch on the rope may have assimilated individual experiences into the socially acquired knowledge on how to operate the present device (Tomasello 1990, Whiten et al. 2004, Greco et al. 2013). It is striking that all but one of the learners, which initially tried to manipulate the rope with its hoof, eventually adopted the behaviour of the demonstrator (Whiten et al. 2004). The learners may therefore have realized that demonstrators were successfully using a particular technique, but found copying the mouth technique difficult. Generally, it is easier to copy the use of hands or hoofs as the animals can see their actions (i.e. perceptual opacity, Byrne 2002, Heyes 2002, Whiten et al. 2004). Therefore animals may have used a hoof simply because they could see it, and used their own existing technique. For example, they may have previously tried to scratch snow from the grass, and applied this technique in the new situation (Tomasello 1990).

It appears that stimulus enhancement and emulation are the two social learning mechanisms used by the horses of the present study. However, this study was not designed to demonstrate a certain social learning mechanism, and this would need to be addressed in future studies.

In this context, we have to discuss procedural differences between the learning and the control experiment. Assuming that humans, as well as conspecifics, can convey social information to horses, one might argue that experimental horses were interested in the experimental procedure for longer than control horses simply because they received twice as many stimulus enhancement cues to approach the feeding apparatus: experimental horses saw both a person and a demonstrator horse operating the feeding apparatus, while control horses only observed a person refilling and closing the drawer. Some horses orient their focus of attention on a human's focus of attention, but do this almost exclusively with familiar persons (Krueger et al. 2011). By using experimenters who were unknown to the horses we tried to minimise their influence. Furthermore, the fact that observers were attracted to the rope area much more quickly than the control horses suggests that the demonstrator's action at the rope may have provided local and stimulus enhancement cues that were important for 
learning the process (Whiten and Ham 1992, Heyes 1994, Galef 1995, Byrne and Russon 1998, Whiten et al. 2004, Guttridge et al. 2013).

\section{The horses' feeding environment}

In general, social learning might help horses to cope with the demands of their complex social environment (Nicol 2002, Murphy and Arkins 2007), but why should horses learn feeding behaviours socially? Changes in the physical environment of horses seem to be easy to predict, with no need for fast adaptations that might require social learning (Byrne and Whiten 1988, Call 2006, Galef and Giraldeau 2001). Food quality changes slowly, and food is fairly equally distributed when resources are abundant (Devenport et al. 2005). However young horses may have to learn innovative feeding strategies in harsh environments, where food is scarce and difficult to reach (Berger 1986, Reader and Laland 2002, Nicol 2002). In fact, there are anecdotal reports of innovative feeding behaviour in natural horse populations, such as horses turning stones to access food underneath (own observation). Similarly, in reintroduction projects, young, zoo-housed Przewalski horses need to learn to feed on bark and to break down trees to better access the bark (own observation). A scientific approach to feeding innovations in horses, and whether

Baer KL, Potter GD, Friend TH, Beaver BV (1983) Observation effects on learning in horses. Appl Animal Ethol 11, 123-129.

http://doi.org/10.1016/0304-3762(83)90121-9

Baker AEM, Crawford BH (1986) Observational learning in horses. Appl Anim Behav Sci 15, 7-13. http://doi.org/10.1016/0168-1591(86)90017-1

Berger J (1986) Wild horses of the Great Basin. University of Chicago Press, Chicago.

Boogert NJ, Reader SM, Laland KN (2006) The relation between social rank, neophobia and individual learning in starlings. Anim Behav 72, 1229-1239. http://doi.org/10.1016/j.anbehav.2006.02.021

Byrne RW (2002) Imitation of novel complex actions: What does the evidence from animals mean? In: Snowdon CT, Roper TJ, Rosenblatt JS (eds) Advances in the study of behavior. Academic Press, San Diego, pp 77-105.

Byrne R, Whiten A (1988) Machiavellian intelligence. Oxford Univ Press, Oxford.

Byrne RW, Russon AE (1998) Learning by imitation: a hierachical approach. Behav Brain Sci 21, 667-721

Call $J$ (2006) Inferences by exclusion in the great apes: the effect of age and species. Anim Cogn 9, 393-403.

http://doi.org/10.1007/s10071-006-0037-4

Cameron EZ, Setsaas TH, Linklater WL (2009) Social bonds between unrelated females increase reproductive success in feral horses. Proc Natl Acad Sci USA 106, 13850-13853. http://doi.org/10.1126/science. 1088580

Carroll J, Murphy CJ, Neitz M, Hoeve JN, Neitz J (2001) Photopigment basis for dichromatic color they are acquired individually or socially, is urgently needed.

\section{Conclusion}

We suggest that horses are capable of social transfer of information, in contrast to previous assumptions (van Schaik 2010), and that young, low ranking and exploratory horses can learn through observing older group members. Misconceptions about the social and ecological factors in the horse's social learning abilities may have hampered previous social learning experiments in this species.

Acknowledgements We thank Michael Tomasello, Kurt Kotrschal, Christian Schloegel, Richard Byrne, Christine Nicol, and Becky Hothersall for helpful discussions, Knut Krüger for helping with statistical analyses, Gudrun Schneider, Andreas Sailer, Anja Schlecht, Magdalena Schneider, and Stephanie Leopold for assistance at the experiments, as well as Sonja und Andreas Nieling, Karin Stadtherr, Tobias Knoll, Alexandra Stupperich, Elisabeth and Marion Klein, Nina Streek, Christina Bachfisch and Andrea Schöpe for providing us with horses. Finally, we would like to thank the Dr. Peter Deubner Stiftung for financial support.

References

vision in the horse. J Vis 1, 80-87.

http://doi.org/10.1167/1.2.2

Chalmeau R, Gallo A (1993) Social constraints determine what is learned in the chimpanzee. Behav Process 28, 173-179.

http://doi.org/10.1016/0376-6357(93)90090-E

Christensen JW, Keeling LJ, Nielsen BL (2005) Responses of horses to novel visual, olfactory and auditory stimuli. Appl Anim Behav Sci 93, 53-65.

http://doi.org/10.1016/j.applanim.2005.06.017

Christensen JW, Rundgren M, Olsson K (2006) Training methods for horses: habituation to a frightening stimulus. Equine Vet J 38, 439-443

Christensen JW, Malmkvist J, Nielsen BL, Keeling LJ (2008) Effects of a calm companion on fear reactions in naive test horses. Equine Vet J 40, 46-50. http://doi.org/10.2746/042516408X245171

Clarke JV, Nicol CJ, Jones R, McGreevy PD (1996) Effects of observational learning on food selection in horses. Appl Anim Behav Sci 50, 177-184. http://doi.org/10.1016/0168-1591(96)01071-4

Coussi-Korbel S, Fragaszy DM (1995) On the relation between social dynamics and social learning. Anim Behav 50, 1441-1453. http://doi.org/10.1016/0003-3472(95)80001-8

Cozzi A, Sighieri C, Gazzano A, Nicol CJ, Baragli P (2010) Post-conflict friendly reunion in a permanent group of horses (Equus caballus). Behav Process 85, 185-190. http://doi.org/10.1016/j.beproc.2010.07.007

Devenport JA, Patterson MR, Devenport LD (2005) Dynamic averaging and foraging decisions in horses (Equus callabus). J Comp Psychol 119, 352- 
358. http://doi.org/10.1037/0735-7036.119.3.352

Dunbar R (2003) Evolution of the social brain. Science 302, 1160-1161.

http://doi.org/10.1126/science.1092116

Dunbar RIM, Shultz S (2007) Evolution in the social brain. Science 317, 1344-1347.

http://doi.org/10.1126/science.1145463

Feist JD, McCullough DR (1976) Behavior patterns and communication in feral horses. Z Tierpsychol 41, 337-371. http://doi.org/10.1111/j.1439-0310.1976.tb00947.x

Galef, BG (1995) Why behaviour patterns that animals learn socially are locally adaptive. Anim Behav 49, 1325-1334. http://doi.org/10.1006/anbe.1995.0164

Galef BGJr, Giraldeau LA (2001) Social influences on foraging in vertebrates: causal mechanisms and adaptive functions. Anim Behav 61, 3-15.

http://doi.org/10.1006/anbe.2000.1557

Geisbauer G, Griebel U, Schmid A, Timney B (2004) Brightness discrimination and neutral point. Can J Zool 82, 660-670. http://doi.org/10.1139/Z04-026

Giraldeau L-A, Lefebvre L (1987) Scrounging prevents cultural transmission of food-finding behaviour in pigeons. Anim Behav 35, 387-394. http://doi. org/10.1016/S0003-3472(87)80262-2

Giraldeau L-A, Valone TJ, Templeton JJ (2002) Potential disadvantages of using socially acquired information. Phil Trans Biol Sci 357, 1559-1566.

http://doi.org/10.1098/rstb.2002.1065

Greco BJ, Brown TK, Andrews JRM, Swaisgood RR, Caine NG (2013) Social learning in captive African elephants (Loxodonta africana africana). Animal Cognition 16, 459-469.

http://doi.org/10.1007/s10071-012-0586-7

Guttridge TL, Dijk S, Stamhuis EJ, Krause J, Gruber SH, Brown C (2013) Social learning in juvenile lemon sharks, Negaprion brevirostris. Animal Cognition 16, 55-64.

http://doi.org/10.1007/s10071-012-0550-6

Hall CA, Cassaday HJ, Derrington AM (2003) The effect of stimulus height on visual discrimination in horses. J Anim Sci 81, 1715-1720

Hanggi EB, Ingersoll JF (2009) Long-term memory for categories and concepts in horses (Equus caballus). Anim Cogn 13, 451-462.

http://doi.org/10.1007/s10071-008-0205-9

Hanggi EB, Ingersoll JF, Waggoner TL (2007) Color vision in horses (Equus caballus): deficiencies identified using a pseudoisochromatic plate test. J Comp Psychol 121, 65-72.

http://doi.org/10.1037/0735-7036.121.1.65

Hare B, Call J, Tomasello M (2001) Do chimpanzees know what conspecifics know? Anim Behav 61, 139-151. http://doi.org/10.1006/anbe.2000.1518

Hemelrijk CK, Wantia J, Gygax L (2005) The construction of dominance order: comparing performance of five methods using an individual-based model. Behaviour 142, 1043-1064. http://doi.org/10.1163/156853905774405290

Heyes CM (1994) Social learning in animals: categories and mechanisms. Biol Rev 69, 207-231. http://doi.org/10.1111/j.1469-185X.1994.tb01506.x

Heyes CM (2002) Transformation and associative theories of imitation. In: Dautenhahn K, Nehaniv CL (eds) Imitation in animals and artefacts. MIT Press, Cambridge, MA., pp 501-523.

Heyes C, Galef BG (1996) Social learning in animals: the roots of culture. Academic Press, Inc., San Diego, CA.

Holekamp KE (2006) Questioning the social intelligence hypothesis. Trends Cognit Sci 11, 65-69. http://doi.org/10.1016/j.tics.2006.11.003

Hopewell L, Leaver L, Lea S, Wills A (2010) Grey squirrels (Sciurus carolinensis) show a feature-negative effect specific to social learning. Anim Cogn 13, 219-227.

http://doi.org/10.1007/s10071-009-0259-3

Houpt KA, Law K, Martinisi V (1978) Dominance hierarchies in domestic horses. Appl Anim Ethol 4, 273283. http://doi.org/10.1016/0304-3762(78)90117-7

Imanishi K (1957) Identification: A process of enculturation in the subhuman society of Macaca fuscata. Primates 1, 1-29-29.

http://doi.org/10.1007/BF01667196

Kerth G (2010) Group decision-making in animal societies. In: Kappeler P (ed) Animal Behaviour: Evolution and Mechanisms. Springer Berlin Heidelberg, pp 241-265.

Krueger K, Flauger B (2008) Social feeding decisions in horses (Equus caballus). Behav Process 78, 7683. http://doi.org/10.1016/j.beproc.2008.01.009

Krueger K, Heinze J (2008) Horse sense: social status of horses (Equus caballus) affects their likelihood of copying other horses' behavior. Anim Cogn 11, 431-439.

http://doi.org/10.1007/s10071-007-0133-0

Krueger K, Flauger B (2011) Olfactory recognition of individual competitors by means of faeces in horse (Equus caballus). Anim Cogn 14, 245-257. http://doi.org/10.1007/s10071-010-0358-1

Krueger K, Flauger B, Farmer K, Maros K (2011) Horses (Equus caballus) use human local enhancement cues and adjust to human attention. Anim Cogn 14, 187-201.

http://doi.org/10.1007/s10071-010-0352-7

König von Borstel U, Euent S, Graf P, König S, Gauly $M$ (2011) Equine behaviour and heart rate in temperament tests with or without rider or handler. Physiol Behav 104, 454-463.

http://doi.org/10.1016/j.physbeh.2011.05.010

Laland KN (2004) Social learning strategies. Learn Behav 32, 4-14

Le Scolan N, Hausberger M, Wolff A (1997) Stability over situations in temperamental traits of horses as revealed by experimental and scoring approaches. Behav Process 41, 257-266. 
http://doi.org/10.1016/S0376-6357(97)00052-1

Lefebvre L, Giraldeau LA (1996) Is social learning an adaptive specialisation? In: Heyes CM; Galef BGJr (eds) Social learning in animals: The root of culture. Academic Press, San Diego, pp 107-128.

Lindberg AC, Kelland A, Nicol CJ (1999) Effects of observational learning on acquisition of an operant response in horses. Appl Anim Behav Sci 61, 187-199. http://doi.org/10.1016/S0168-1591(98)00184-1

Linklater WL (2000) Adaptive explanation in socio-ecology: lessons from the Equidae. Biol Rev 75, 1-20. http://doi.org/10.1111/j.1469-185X.1999.tb00039.x

Macuda T, Timney B (1999) Luminance and chromatic discrimination in the horse (Equus caballus). Behav Process 44, 301-307

McDonnell SM (2003) The equid ethogram: A practical field guide to horse behavior. Eclipse Press, Lexington, Kentucky.

McDonnell SM, Haviland JCS (1995) Agonistic ethogram of the equid bachelor band. Appl Anim Behav Sci 43, 147-188.

http://doi.org/10.1016/0168-1591(94)00550-X

Mersmann D, Tomasello M, Call J, Kaminski J, Taborsky M (2011) Simple mechanisms can explain social learning in domestic dogs (Canis familiaris). Ethology 117, 675-690. http://doi.org/10.1111/j.1439-0310.2011.01919.x

Mettke-Hofmann C, Winkler H, Leisler B (2002) The significance of ecological factors for exploration and neophobia in parrots. Ethology 108, 249-272. http://doi.org/10.1046/j.1439-0310.2002.00773.x

Momozawa Y, Ono T, Sato F, Kikusui T, Takeuchi Y, Mori Y, Kusunose R (2003) Assessment of equine temperament by a questionnaire survey to caretakers and evaluation of its reliability by simultaneous behavior test. Appl Anim Behav Sci 84, 127-138

Momozawa Y, Kusunose R, Kikusui T, Takeuchi Y, Mori $Y(2005)$ Assessment of equine temperament questionnaire by comparing factor structure between two separate surveys. Appl Anim Behav Sci 92, 77-84. http://doi.org/10.1016/j.applanim.2004.11.006

Murphy J, Arkins S (2007) Equine learning behaviour. Behav Process 76, 1-13.

http://doi.org/10.1016/j.beproc.2006.06.009

Murphy LB (1978) The practical problems of recognizing and measuring fear and exploration behaviour in the domestic fowl. Anim Behav 26, Part 2, 422431. http://doi.org/10.1016/0003-3472(78)90059-3

Nicol CJ (2002) Equine learning: progress and suggestions for future research. Appl Anim Behav Sci 78, 193-208.

http://doi.org/10.1016/S0168-1591(02)00093-X

Nicol CJ, Pope SJ (1999) The effects of demonstrator social status and prior foraging success on social learning in laying hens. Anim Behav 57, 163-171. http://doi.org/10.1006/anbe.1998.0920

Pongrácz P, Miklósi Á, Kubinyi E, Gurobi K, Topál J, Csányi V (2001) Social learning in dogs: the effect of a human demonstrator on the performance of dogs in a detour task. Anim Behav 62, 1109-1117

Pongrácz P, Vida V, Bánhegyi P, Miklósi Á (2008) How does dominance rank status affect individual and social learning performance in the dog (Canis familiaris)? Anim Cogn 11, 75-82.

http://doi.org/10.1007/s10071-007-0090-7

Proops L, McComb K, Reby D (2009) Cross-modal individual recognition in domestic horses (Equus caballus). Proc Natl Acad Sci USA 106, 947-951. http://doi.org/10.1073/pnas.0809127105

R Development Core Team (2012) R: A language and environment for statistical computing. http://www.Rproject.org

Reader SM, Laland KN (2002) Social intelligence, innovation, and enhanced brain size in primates. Proc Natl Acad Sci USA 99, 4436-4441.

http://doi.org/10.1073/pnas.062041299

Russon AE, Galdikas BMF (1995) Constraints on great apes' imitation: Model and action selectivity in rehabilitant orangutan (Pongo pygmaeus) imitation. J Comp Psychol 109, 5-17.

http://doi.org/10.1037/0735-7036.109.1.5

Schmidt M, Lipson H (2009) Distilling free-form natural laws from experimental data. Science 324, 81-85. http://doi.org/10.1126/science.1165893

Schneider G, Krueger K (2012) Third-party interventions keep social partners from exchanging affiliative interactions with others. Anim Behav 83, 377387. http://doi.org/10.1016/j.anbehav.2011.11.007

Sherry DF, Galef JrBG (1984) Cultural transmission without imitation: Milk bottle opening by birds. Anim Behav 32, 937-938.

http://doi.org/10.1016/S0003-3472(84)80185-2

Tyler SJ (1972) The behaviour and social organisation of the new forest ponies. Anim Behav Monogr 5, 85-196

Valone TJ, Templeton JJ (2002) Public information for the assessment of quality: a widespread social phenomenon. Phil Trans Biol Sci 357, 1549-1557

van Schaik CP (2010) Social learning and culture in animals. In: Kappeler P (ed) Animal behaviour: Evolution and mechanisms. Springer Berlin Heidelberg, pp 623-653.

Vidament M, Yvon JM, Roche H, Le Bon H, Menard C, Delfosse A, Dubois C, Sabot J, Lansade L (2012) Temperament of stallions: relation with age, breed and level of riders. Proc 2 Int Equine Sci Mtg.

Whiten A, Ham R (1992) On the nature and evolution of imitation in the animal kingdom: reappraisal of a century of research. Adv Study Behav 21, 239-283

Whiten A, Horner V, Litchfield CA, Marshall-Pescini S (2004) How do apes ape? Learn Behav 32, 36-52

Wilson SD, Clark AB, Coleman K, Dearstyne T (1994) Shyness and boldness in humans and other animals. Trends Ecol Evol 9, 442-446.

http://doi.org/10.1016/0169-5347(94)90134-1 


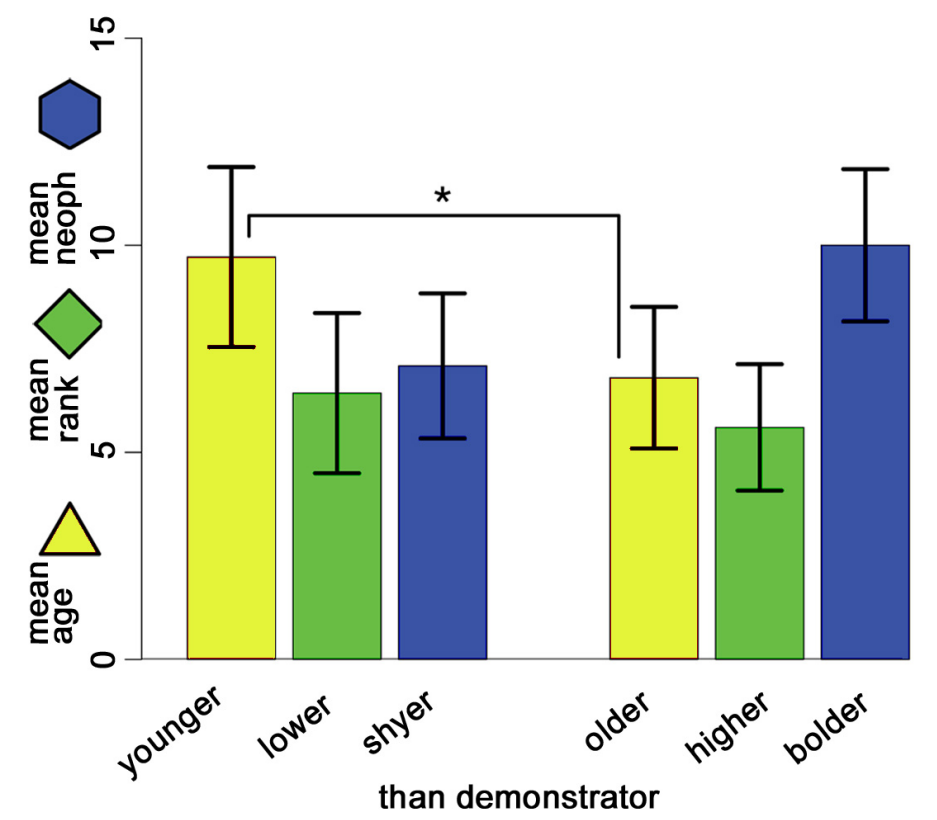

Fig. ESM 1 Relationships between learner and demonstrator horses

Learners are significantly younger then demonstrators, but no significant difference was found between learner and demonstrator horses in social rank or exploration (exploration index $=$ explor). The columns depict the mean and the whiskers the SD. * stands for $p \leq 0.05$.

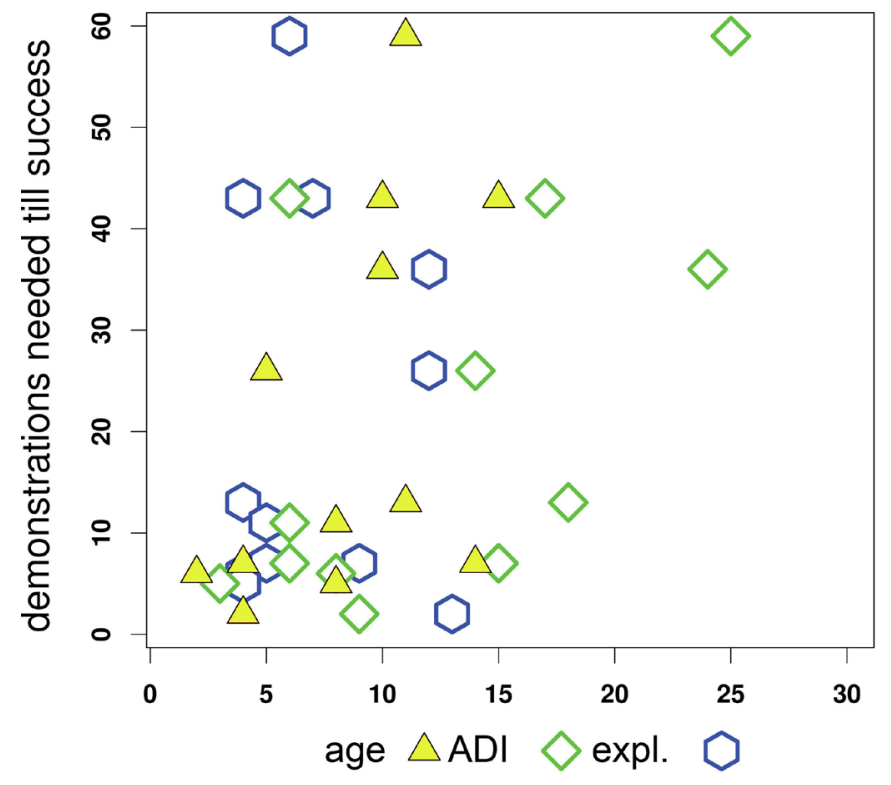

Fig. ESM 2 Effects on box-opening speed Age, but not social rank (ADI) or exploration (exploration index = explor), correlated significantly with the numbers of demonstrations learners needed to open the feed drawer the first time. The number of trials that were needed to accomplish learning criteria from this point are depicted in figure 5 . To enhance the readability of the graph, ADI values were multiplied by 30 . The significant symbols for age are filled, and the insignificant symbols for rank (ADI) and exploration (explor) are unfilled. 
learner (L)

t $\mathrm{r}$ i a 1

or non- \# of trials trial first learning technique in Age Sex Rank Exploration learner (N) participation opening critera use firs

\begin{tabular}{|cccc|}
\hline observer & Enya & 4 & Female \\
\hline observer & Emily & 5 & Female \\
demonstrator & Principessa & $\mathbf{8}$ & Female \\
observer & Elrond & 10 & Male \\
observer & Priciosa & 10 & Female \\
observer & Mogol & 25 & Male \\
\hline
\end{tabular}

$\begin{array}{lc}6 & 2,17 \\ 4 & 2 \\ \mathbf{5} & \mathbf{1 , 5} \\ 2 & 2 \\ 3 & 1,5 \\ 1 & 1,17\end{array}$

L 29

29

L

NA

$\mathrm{L}$
$\mathrm{N}$
$\mathrm{N}$

$\mathrm{N}$

46
NA
71
52
12

$\begin{array}{cc}2 & 29 \\ 26 & 46 \\ \mathbf{N A} & \mathbf{N A} \\ 36 & 71 \\ 0 & 0 \\ 0 & 0\end{array}$

$\begin{array}{cc}29 & \begin{array}{c}\text { hoof } \\ \text { mouth / } \\ \text { hoof }\end{array} \\ 46 & \text { NA } \\ \text { NA } & \text { mouth } \\ 71 & \text { NA } \\ 0 & \text { NA }\end{array}$

2

\begin{tabular}{|cccl|}
\hline observer & Brenhines & 2 & Female \\
observer & Bijou & 11 & Female \\
\hline demonstrator & Bea & $\mathbf{1 6}$ & Female \\
observer & Biwel & 17 & Female \\
\hline
\end{tabular}

$\begin{array}{ll}4 & 0,66 \\ 2 & 1,66 \\ 1 & 0,66\end{array}$

0,66

1,66

0,66

0,16

N

mouth /

\begin{tabular}{|cccc}
\hline observer & Toffee & 4 & Female \\
observer & Sarastro & 7 & Male \\
observer & Fiona & 8 & Female \\
observer & Vittoria & 8 & Female \\
observer & Plainsman & 8 & Male \\
observer & Giardino & 10 & Male \\
observer & Gyula & 11 & Female \\
observer & Csaba & 11 & Male \\
\hline demonstrator & Feodora & $\mathbf{1 2}$ & Female \\
\hline observer & Savanna & 14 & Female \\
observer & Nikolas & 16 & Male \\
observer & Eckos & 21 & Male \\
\hline
\end{tabular}

$\begin{array}{cc}10 & 1,5 \\ 3 & 0,67 \\ 9 & 0,17 \\ 11 & 0,83 \\ 12 & 0,67 \\ 6 & 0,67 \\ 2 & 1 \\ 5 & 0,67 \\ 4 & \mathbf{0 , 6 7} \\ 7 & 0,83 \\ 1 & 0,33 \\ 8 & 0,5\end{array}$

$\begin{array}{ll}\text { L } & 44 \\ \text { N } & 70 \\ \text { N } & \text { NA }\end{array}$

44
70
NA
100

$\begin{array}{ccc}6 & 44 & \text { hoof } \\ 0 & 0 & \text { NA } \\ \text { NA } & \text { NA } & \text { NA } \\ 0 & 0 & \text { NA }\end{array}$
NA NA mouth / hoof

L 29

N 74

$\mathrm{N} \quad 120$

L 34

L 29

L 69

L 79

L 36

NA NA

L

29

$\mathrm{N} \quad 60$

N 70

\section{9 \\ 60
70}

$\begin{array}{cc}7 & 29 \\ 0 & \\ 21 & \\ 11 & \\ 5 & 29 \\ 43 & 69 \\ 59 & 79 \\ 13 & 36 \\ \text { NA } & \text { NA } \\ 7 & 29 \\ 0 & \\ 0 & \end{array}$

29
0
0
34
29
69
79
36
$\mathbf{N A}$
29
0
0

NA mouth mouth mouth mouth mouth mouth

observer

Anouschka 11 Female

$5 \quad 0,83$

1

$\begin{array}{cc}\mathrm{N} & 12 \\ \mathbf{N A} & \mathbf{N A} \\ \mathrm{N} & 64 \\ \mathrm{~N} & 63 \\ \mathrm{~N} & 55\end{array}$

120
NA
64
63
55

$\begin{array}{cc}0 & 0 \\ \mathbf{N A} & \mathbf{N A} \\ 0 & 0 \\ 0 & 0 \\ 0 & 0\end{array}$

NA

hoof

NA

NA

$\begin{array}{cccc}\text { demonstrator } & \text { Peppermint } & \mathbf{1 9} & \text { Male } \\ \text { observer } & \text { Alexia } & 25 & \text { Female } \\ \text { observer } & \text { Sara } & 27 & \text { Female } \\ \text { observer } & \text { Farina } & 28 & \text { Female }\end{array}$

\begin{tabular}{cccl} 
observer & La Belle & 15 & Female \\
demonstrator & Traum & $\mathbf{1 6}$ & Female \\
observer & Francis & 17 & Female \\
\hline
\end{tabular}

3
2
1

\begin{tabular}{ccc}
1,27 & $\mathrm{~L}$ & 88 \\
$\mathbf{1 , 1 7}$ & $\mathbf{N A}$ & $\mathbf{N A}$ \\
1,3 & $\mathrm{~N}$ & 81 \\
\hline
\end{tabular}

\begin{tabular}{cc}
43 & 88 \\
NA & NA \\
0 & 0 \\
\hline
\end{tabular}

mouth / NA 
Table ESM 6 Data control horses

\begin{tabular}{|c|c|c|c|c|c|c|c|c|}
\hline Name & age & sex & $\begin{array}{l}\text { learner or } \\
\text { non-learner }\end{array}$ & $\begin{array}{l}\# \text { of trials } \\
\text { participation }\end{array}$ & $\begin{array}{l}\text { trial first } \\
\text { opening }\end{array}$ & $\begin{array}{l}\mathrm{t} \quad \mathrm{r} \quad \mathrm{i} \\
\text { le a r n } \\
\text { critera }\end{array}$ & $\begin{array}{ll}\text { a } & 1 \\
\text { in } g\end{array}$ & $\begin{array}{l}\text { technique } \\
\text { in use first }\end{array}$ \\
\hline Fritzi & & 7 male & non-learner & 35 & 0 & & 0 & Mouth \\
\hline Adlon & & 6 male & learner & 66 & 19 & & 66 & Mouth \\
\hline Fabelbär & & 7 male & non-learner & 41 & 0 & & 0 & Mouth \\
\hline Maybe & & 2 female & non-learner & 17 & 0 & & 0 & Mouth \\
\hline Missou & 3 & 3 female & Learner & 80 & 59 & & 80 & mouth \\
\hline Santana & 4 & 4 female & non-learner & 64 & 0 & & 0 & Mouth \\
\hline Candy & 6 & 6 male & non-learner & 32 & 0 & & 0 & Mouth \\
\hline Roma & 12 & 2 female & non-learner & 17 & 0 & & 0 & Mouth \\
\hline Wespe & 17 & 7 female & non-learner & 45 & 0 & & 0 & Mouth \\
\hline Leni & 15 & 5 female & non-learner & 15 & 0 & & 0 & Mouth \\
\hline Alice & 22 & 2 female & non-learner & 34 & 0 & & 0 & Mouth \\
\hline Cola & 22 & 2 female & non-learner & 22 & 0 & & 0 & Mouth \\
\hline Komet & 18 & 8 male & non-learner & 41 & 0 & & 0 & Mouth \\
\hline Sandro & 25 & 5 male & non-learner & 28 & 0 & & 0 & Mouth \\
\hline
\end{tabular}

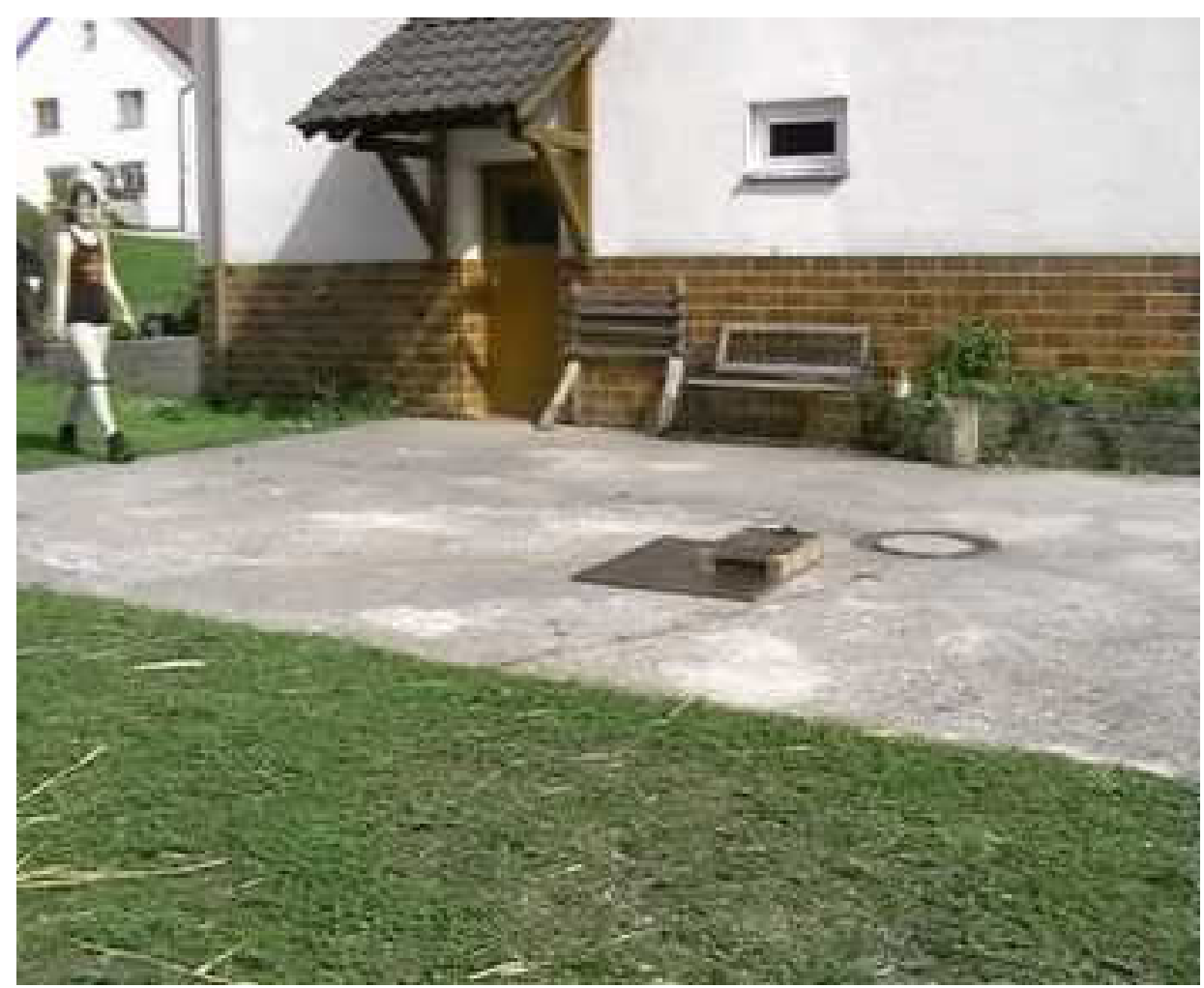

Video ESM 3: Demonstrator Training

The training phase of independent demonstration is reached. The demonstrator is first led to the experimental apparatus and then approaches the apparatus and opens the drawer independently by itself 


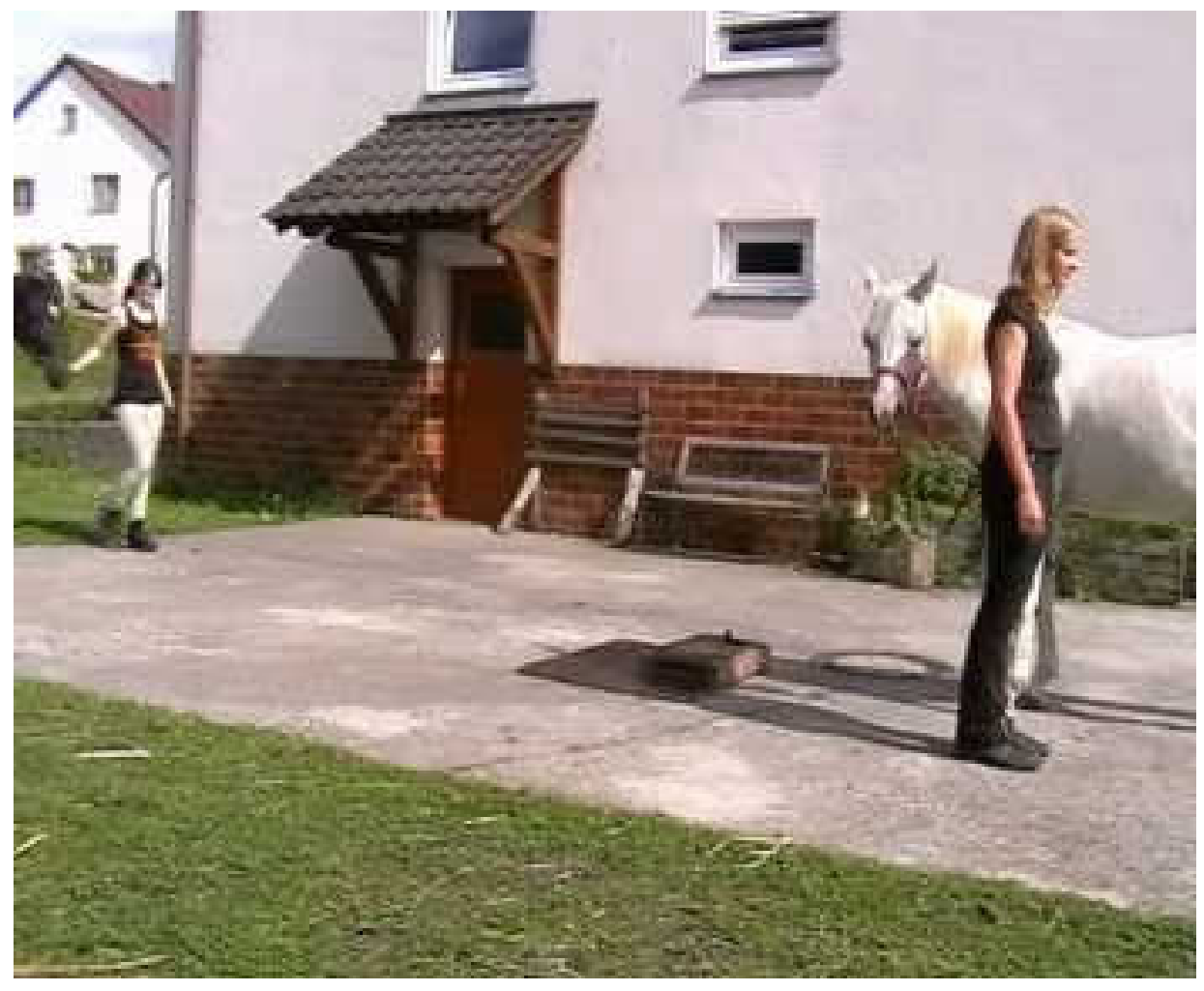

Video ESM 4: Successful learner

A learner horse pulls the rope, opens and feeds from the drawer after demonstration 